\title{
Estimativa da área foliar de pessegueiro por método não-destrutivo
}

\author{
Non-destructive leaf area estimation in peach tree \\ Marcos Robson Sachet ${ }^{\mathrm{I}}$ Gener Augusto Penso ${ }^{\mathrm{I}}$ Rafael Henrique Pertille ${ }^{\mathrm{II}}$ \\ Marieli Teresinha GuerreziII Idemir Citadin ${ }^{I^{*}}$
}

\begin{abstract}
A predição de valores de área foliar (AF) sem RESUMO

a destruição de plantas é de grande interesse nas pesquisas agronômicas. Neste trabalho, foram desenvolvidos e testados três modelos de predição de AF, utilizando-se a largura (L), o comprimento (C) ou em ambas as dimensões da folha de pessegueiro 'BRS Kampai'. Testou-se também um modelo genérico de DEMIRSOY et al. (2004), proposto para determinar AF em pessegueiro e desenvolvido nas condições de cultivo da Turquia. $O$ uso de apenas uma dimensão, visando a reduzir a onerosidade nas avaliações, não permite predições adequadas e podem levar a erros estatísticos por alterar a variabilidade dos dados em relação às $A F$ reais. $O$ modelo não destrutivo proposto neste trabalho foi “ $A F=6,852+0,823 L^{*} C-0,691 L^{2}-1,614 C / L$ ", que pode ser indicado para estimar satisfatoriamente a AF em substituição à análise destrutiva e apresentou ganhos de estimação, quando comparado ao modelo genérico de DEMIRSOY et al. (2004).
\end{abstract}

Palavras-chave: Prunus persica, modelo, validação, análise regressão stepwise.

\section{ABSTRACT}

The prediction of leaf area (LA) without causing damage to the plant is a subject of great interest in agricultural research. In this study, it was developed and tested three models based on the length $(L)$, width $(W)$ or both of these leaf dimensions of 'BRS Kampai' peach trees. Further to this, a DEMIRSOY et al. (2004) generic model proposed to determine leaf area in peach trees growing in Turkey was also tested. The use of only one dimension, which aims to reduce the effort required by the assessor, does not permit adequate predictions and may lead to statistical errors by changing the variability of the original LA data. The model proposed in this study was " $L A=6.852+0.823 L * W-0.691 W^{2}-1.614 L / W "$, this model can be used to satisfactorily estimate the $L A$, replacing the destructive analysis, and provided a better prediction than the generic model proposed by DEMIRSOY et al. (2004).
Key words: Prunus persica, model, validation, stepwise regression analysis.

A estimativa de área foliar (AF) é uma importante ferramenta de pesquisa em experimentos sobre a produção vegetal. É uma variável necessária para a compreensão da respiração, fotossíntese, utilização de nutrientes, floração, frutificação e produtividade (DEMIRSOY, 2009). Para estimála, muitos métodos foram desenvolvidos. Métodos diretos ou destrutivos com a remoção das folhas, e métodos não destrutivos ou indiretos com o uso de equações e valores das dimensões foliares obtidas em campo. O uso de métodos não destrutivos ganha importância em pequenas populações de plantas, onde é possível realizar medições ao longo do cultivo e que se pretende utilizar essas plantas para avaliação posterior. Este método é rápido e mais fácil de ser executado, apresentando boa precisão para o estudo do crescimento de plantas (ANTUNES et al., 2008; DEMIRSOY, 2009; BOSCO et al., 2012).

Visando à necessidade de um método não destrutivo para a cultura de pessegueiro, o objetivo deste trabalho foi desenvolver um modelo para estimar a AF e testar um modelo genérico desenvolvido por DEMIRSOY et al. (2004) nas condições da Turquia.

As avaliações foram realizadas na área experimental da UTFPR, no município de Pato Branco, Paraná, altitude de $764 \mathrm{~m}$, latitude de $26^{\circ} 10^{\prime} 38^{\prime \prime} \mathrm{S}$ e longitude $52^{\circ} 41 ' 24^{\prime \prime} \mathrm{W}$. Optou-se pelo estudo na IPrograma de Pós-graduação em Agronomia, Universidade Tecnológica Federal do Paraná (UTFPR), Via do Conhecimento, Km 01,
85503-390, Pato Branco, PR, Brasil. E-mail: idemir@utfpr.edu.br. *Autor para correspondência.

IIUTFPR, Pato Branco, PR, Brasil.

Recebido 09.02.15 Aprovado 08.04.15 Devolvido pelo autor 22.07.15 
cultivar 'BRS Kampai' por sua alta adaptabilidade e estabilidade quanto à brotação e formação de brindilas (SCARIOTTO et al., 2013), produção e frutificação (CITADIN et al., 2014), todas características necessárias para a expansão da cultura em regiões subtropicais. Em 30 de julho de 2014, foi implantado um experimento com pessegueiro 'BRS Kampai', enxertado sobre 20 porta-enxertos distintos, com espaçamento $5,5 \times 2,5 \mathrm{~m}$, com cinco repetições (plantas).

Em janeiro de 2015, foram coletadas 10 folhas totalmente expandidas de cada planta totalizando 1000 unidades. Para a estimativa de área foliar $\left(\mathrm{AF}, \mathrm{em} \mathrm{cm}^{2}\right)$, largura do limbo $(\mathrm{cm})$ e comprimento do limbo $(\mathrm{cm})$, foi utilizado o software ImageJ (open source). As folhas foram digitalizadas com alta resolução junto com uma régua milimétrica tomada como referencial para configuração do software (pixel $\mathrm{cm}^{-1}$ ).

As dimensões das folhas foram separadas aleatoriamente em dois conjuntos de dados, com 600 e 400 unidades, para estimar os parâmetros e a validação dos modelos, respectivamente. Os modelos e respectivos coeficientes de determinação $\left(\mathrm{R}^{2}\right)$ foram gerados pelo programa Genes (CRUZ, 2013). Considerou-se como variável dependente a área foliar real e, como variáveis independentes, as dimensões foliares: largura (L), comprimento (C) e relativas $\left(\mathrm{L}^{2}, \mathrm{C}^{2}, \mathrm{C}^{*} \mathrm{~L}, \mathrm{C} / \mathrm{L}\right.$ e $\mathrm{C}^{2} /$ $\mathrm{L}^{2}$ ). Inclui-se, também, nesses procedimentos o modelo proposto por DEMIRSOY et al. (2004), em que $\mathrm{AF}=$ $0,5+0,23 \mathrm{C} / \mathrm{L}+0,67 \mathrm{C} * \mathrm{~L}$. Para as variáveis relativas, optou-se pelo procedimento de análise de regressão stepwise (passo a passo) do Programa Genes (CRUZ, 2013) com inclusão da variável quando o seu coeficiente apresentasse $\mathrm{P} \leq 0,001$.

Para validação dos modelos, foram utilizadas estatísticas comparando os valores de AF real com AF estimada no conjunto com 400 unidades. Efetuou-se o cálculo do erro absoluto médio (EAM), conforme HINNAH et al. (2014), e índice de confiança (c), de acordo com MORGADO et al. (2013).

Os modelos foram testados quanto à repetibilidade pelo Programa Genes (CRUZ, 2013). Para isso, utilizaram-se valores reais e estimados de $\mathrm{AF}$, em delineamento inteiramente ao acaso com 20 genótipos de porta-enxerto, tendo 'BRS Kampai' como cultivar copa e 50 repetições (folhas), as folhas coletadas nas plantas foram processadas conforme descrito anteriormente. Para análise dos dados, assumiu-se o método baseado na ANOVA com um único fator $\left(\mathrm{Y}_{\mathrm{ij}}=\mu+\mathrm{G}_{\mathrm{i}}+\mathrm{E}_{\mathrm{ij}}\right)$. Determinou-se o coeficiente de repetibilidade ( $\breve{\mathrm{r}}$ ) para o número de medições realizadas, número de medições necessárias $\left(\mathrm{n}_{0}\right.$, arredondado para cima) para uma predição adequada e valor do teste $\mathrm{F}$.
O conjunto de dados utilizados pertence aos intervalos: $\mathrm{AF}\left[7,8\right.$ a $\left.55,8 \mathrm{~cm}^{2}\right], \mathrm{L}$ [1,9 a $\left.6,3 \mathrm{~cm}\right] \mathrm{e}$ C [5,2 a 19,0cm]. Foram desenvolvidos três modelos (Tabela 1) e testado o modelo desenvolvido para pessegueiro por DEMIRSOY et al. (2004). Segundo a tabela de interpretação de desempenho de MORGADO et al. (2013), o Mod. 1 foi considerado bom, enquanto os outros três modelos podem ser considerados ótimos. Essa interpretação, somada ao menor $\mathrm{R}^{2}$ e maior EAM torna imprecisa a aplicação do Mod. 1.

Para acurácia de $90 \%$ e $95 \%$, é necessário, respectivamente, 101 e 212 mensurações de AF obtidas pelo método destrutivo (Tabela 2). O Mod. 1 teve coeficiente de repetibilidade baixo e aumento de $\eta_{0}$. Quando aplicado somente L, ocorre redução do valor de $\mathrm{F}$ que pode levar ao erro tipo II (rejeitar $\mathrm{H}_{1}$ quando $\mathrm{H}_{1} \neq \mathrm{H}_{0}$ ) e também ao aumento do número de medições $\left(\eta_{0}\right)$. Para o Mod. 2 (somente C) ocorre elevação do $\mathrm{F}$, levando ao erro tipo I (rejeitar $\mathrm{H}_{0}$ quando $\mathrm{H}_{1}=\mathrm{H}_{0}$ ). Os dois modelos são considerados inadequados por não representarem a variabilidade encontrada nos dados reais.

O Mod. 3, com L e C, expressa os valores mais próximos de $\eta_{0}$ e $F$ comparados aos reais, necessitando 106 ou 222 mensurações, respectivamente, para acurácia de $90 \%$ e $95 \%$. Dessa forma, o modelo permitiu a manutenção da variabilidade encontrada na população.

Foi observado que a utilização de apenas uma dimensão foliar, com menor eficiência de predição, pode levar a erros estatísticos, concordando com os resultados de SOUZA et al. (2014), que, em estudo com

Tabela 1 - Modelos para estimativa da área foliar (AF, $\mathrm{cm}^{2}$ folha $\left.{ }^{-1}\right)$ de pessegueiro 'BRS Kampai' e seus respectivos coeficientes de determinação ajustado $\left(\mathrm{R}^{2}\right)$, erro absoluto médio (EAM) e desempenho (c) em função das dimensões das folhas: largura (L) e comprimento (C) do limbo. UTFPR, Campus Pato Branco, 2015.

\begin{tabular}{|c|c|c|c|}
\hline Equação & $\mathrm{R}_{\text {Ajustado }}^{2}$ & EAM & $\mathrm{c}$ \\
\hline $\begin{array}{l}\text { (Mod. 1) } \mathrm{AF}=-17,73+13,31 \mathrm{~L} \\
\mathrm{DP}=(0,326)^{* * *}\end{array}$ & 72,25 & 3,788 & 0,739 \\
\hline $\begin{array}{l}\text { (Mod. 2) } \mathrm{AF}=-14,34+3,44 \mathrm{C} \\
\mathrm{DP}=(0,058)^{* * *}\end{array}$ & 84,79 & 2,657 & 0,893 \\
\hline $\begin{array}{l}\text { (Mod. 3) } \mathrm{AF}=6,852+0,823 \mathrm{LC} \\
-0,691 \mathrm{~L}^{2}-1,614 \mathrm{C} / \mathrm{L}\end{array}$ & 96,44 & 1,242 & 0,971 \\
\hline $\begin{array}{l}\mathrm{DP}=(0,027)^{* * *}(0,091)^{* * *} \\
(0,332)^{* * *}\end{array}$ & & & \\
\hline $\begin{array}{l}\text { (Demirsoy et al. 2004) AF }=-0,5 \\
+0,67 \mathrm{LC}+0,23 \mathrm{C} / \mathrm{L}\end{array}$ & 94,51 & 1,490 & 0,962 \\
\hline
\end{tabular}

$\mathrm{DP}=$ Desvio associado ao coeficiente angular; ***Significância do coeficiente angular ao modelo $(\mathrm{P}<0,001)$. 
Tabela 2 - Estimativas dos coeficientes de repetibilidade (ř), número de medições necessárias $\left(\eta_{0}\right)$, com acurácia de 90 e $95 \%$ e valor do teste $\mathrm{F}$ para área foliar (AF, $\mathrm{cm}^{2}$ folha ${ }^{-1}$ ), estimada pelos modelos e real em pessegueiro 'BRS Kampai', enxertado sobre 20 porta-enxertos distintos. UTFPR, Campus Pato Branco, 2015

\begin{tabular}{lcccc}
\hline Equação & $\check{\mathrm{r}}$ & $\eta_{0}(90 \%)$ & $\eta_{0}(95 \%)$ & Valor F \\
\hline $\mathrm{AF}=-17,73+13,31 \mathrm{~L}$ & 0,0469 & 183 & 387 & 3,46 \\
$\mathrm{AF}=-14,34+3,44 \mathrm{C}$ & 0,1371 & 57 & 120 & 8,94 \\
$\mathrm{AF}=6,852+0,823 \mathrm{LC}-$ & 0,0789 & 106 & 222 & 5,28 \\
$\begin{array}{l}0,691 \mathrm{~L}^{2}-1,614 \mathrm{C} / \mathrm{L} \\
\mathrm{AF}=-0,5+0,67 \mathrm{LC}+\end{array}$ & 0,0730 & 115 & 242 & 4,94 \\
$\begin{array}{l}0,23 \mathrm{C} / \mathrm{L} \\
\begin{array}{l}\text { Área real (método } \\
\text { destrutivo) }\end{array}\end{array}$ & 0,0825 & 101 & 212 & 5,49 \\
\hline
\end{tabular}

a cultura da figueira, afirmou que as análises conjuntas das medidas lineares de $\mathrm{C}$ e $\mathrm{L}$ permitem melhores coeficientes de determinação, quando comparados a análises com medidas lineares isoladas.

O modelo proposto por DEMIRSOY et al. (2004) apresenta boa validação (6 cultivares) nas condições da Turquia. Esse modelo apresentou valores próximos aos reais, mas com menor qualidade de predição, comparado ao Mod. 3. Dessa forma, nas condições em que foi realizado o estudo, o Mod. 3 $\left(\mathrm{AF}=6,852+0,823 \mathrm{~L} * \mathrm{C}-0,691 \mathrm{~L}^{2}-1,614 \mathrm{C} / \mathrm{L}\right)$ pode ser indicado para estimar satisfatoriamente a área foliar em substituição à análise destrutiva.

\section{REFERÊNCIAS}

ANTUNES, W.C. et al. Allometric models for non-destructive leaf area estimation in coffee (Coffea arabica and Coffea canephora). Annals of Applied Biology, v.153, n.1, p.33-40, 2008. Disponível em: <http://dx.doi.org/10.1111/j.1744-7348.2008.00235.x>. Acesso em: 05 fev. 2015. doi: 10.1111/j.1744-7348.2008.00235.x.

BOSCO, L.C. et al. Seleção de modelos de regressão para estimar a área foliar de macieiras 'Royal Gala' e 'Fuji Suprema' sob tela antigranizo e em céu aberto. Revista Brasileira de Fruticultura, v.34, n.2, p.504-514, 2012. Disponível em: <http://dx.doi. org/10.1590/S0100-29452012000200024>. Acesso em: 05 fev. 2015. doi: 10.1590/S0100-29452012000200024.

CITADIN, I. et al. Adaptability and stability of fruit set and production of peach trees in a subtropical climate. Scientia Agricola, v.71, n.2, p.133-138, 2014. Disponível em: <http:// dx.doi.org/10.1590/S0103-90162014000200007>. Acesso em: 05 fev. 2015. doi: 10.1590/S0103-90162014000200007.

CRUZ, C.D. GENES - a software package for analysis in experimental statistics and quantitative genetics. Acta Scientiarum, v.35, n.3, p.271-276, 2013.

DEMIRSOY, H. et al. Non-destructive leaf area estimation in peach. European Journal of Horticultural Science, v.69, n.4, p.144-146, 2004. Disponível em: <http://www.pubhort.org/ ejhs/2004/file_15102.pdf>. Acesso em: 05 fev. 2015.

DEMIRSOY, H. Leaf area estimation in some species of fruit tree by using models as a non-destructive method. Fruits, v.64, p.45-51, 2009. Disponível em: $<$ http://dx.doi.org/10.1051/fruits:2008049>. Acesso em: 05 fev. 2015. doi: 10.1051/fruits:2008049.

HINNAH, F.D. et al. Leaf area of eggplant according to leaf dimensions. Bragantia, v.73, n.3, p.213-218, 2014. Disponível em: <http://dx.doi.org/10.1590/1678-4499.0083>. Acesso em: 05 fev. 2015. doi: 10.1590/1678-4499.0083.

MORGADO, M.A.D. et al. Estimação da área foliar por método não destrutivo, utilizando medidas lineares das folhas de espécies de Passiflora. Revista Ceres, v.60, n.5, p.662667, 2013. Disponível em: <http://dx.doi.org/10.1590/S0034737X2013000500009>. Acesso em: 05 fev. 2015. doi: 10.1590/ S0034-737X2013000500009.

SCARIOTTO, S. et al. Adaptability and stability of 34 peach genotypes for leafing under Brazilian subtropical conditions. Scientia Horticulturae, v.155, p.111-117, 2013. Disponível em: $<$ http://dx.doi.org/10.1016/j.scienta.2013.03.019>. Acesso em: 03 fev. 2015. doi: 10.1016/j.scienta.2013.03.019.

SOUZA, A.P. et al. Estimativas da área da folha de figueiras 'Roxo de Valinhos' usando dimensões lineares do limbo foliar. Ciência Rural, v.44, n.7, p.1172-1179, 2014. Disponível em: <http:// dx.doi.org/10.1590/0103-8478cr20130699>. Acesso em: 05 fev. 2015. doi: 10.1590/0103-8478cr20130699. 